RECENT ACTIVITIES OF THE

NUCLEAR SMUGGLING

INTERNATIONAL TECHNICAL

WORKING GROUP TO THWART

ILLICIT TRAFFICKING

D. K. Smith, T. Biro, B. Chartier, K. Mayer, S.

Niemeyer, P. Thompson

October 30, 2007 
This document was prepared as an account of work sponsored by an agency of the United States government. Neither the United States government nor Lawrence Livermore National Security, LLC, nor any of their employees makes any warranty, expressed or implied, or assumes any legal liability or responsibility for the accuracy, completeness, or usefulness of any information, apparatus, product, or process disclosed, or represents that its use would not infringe privately owned rights. Reference herein to any specific commercial product, process, or service by trade name, trademark, manufacturer, or otherwise does not necessarily constitute or imply its endorsement, recommendation, or favoring by the United States government or Lawrence Livermore National Security, LLC. The views and opinions of authors expressed herein do not necessarily state or reflect those of the United States government or Lawrence Livermore National Security, LLC, and shall not be used for advertising or product endorsement purposes.

This work performed under the auspices of the U.S. Department of Energy by Lawrence Livermore National Laboratory under Contract DE-AC52-07NA27344. 


\title{
Recent activities of the Nuclear Smuggling International Technical Working Group to thwart illicit trafficking
}

\author{
David K. Smith ${ }^{1}$, Tamás Bíró ${ }^{2}$, Bernard Chartier ${ }^{3}$, Klaus Mayer ${ }^{4}$, Sidney \\ Niemeyer ${ }^{1}$, Paul Thompson ${ }^{5}$
}

Nuclear Smuggling International Technical Working Group Executive Committee
1 Lawrence Livermore National Laboratory, P.O. Box 808, Livermore, CA 94550, USA
2 Institute of Isotopes, P.O. Box 77, H 1525 Budapest, Hungary
3 CEA-DAM DACE, B.P. 12, Bruyères-le Chatel, France
4 European Commission, JRC, Institute for Transuranium Elements, P.O. Box
234076125 Karlsruhe, Germany
$5 \quad$ AWE Aldermaston, RG7 4PR, Aldermaston, UK

\begin{abstract}
The Nuclear Smuggling International Technical Working Group (ITWG) is an informal association of nuclear forensic practitioners working in partnership with law enforcement, first responder, and nuclear regulatory professionals that cooperate to deter the illicit trafficking of nuclear materials. The objective of the ITWG is to advance the science of nuclear forensics and to provide a common approach and effective technical solutions to governments who request assistance. The ITWG was chartered in 1996 and since that time 30 nations and organizations have participated in 12 annual meetings and two analytical round-robin trials involving plutonium and highly enriched uranium. A third analytical round-robin as well as several table-top exercises are planned for later in 2007-2008. International interest in the ITWG has grown in over the past five years measured by the number of participants at its annual meetings. This growth has spawned the ITWG Nuclear Forensics Laboratories as a companion technical affiliate focusing exclusively on the scientific aspects of nuclear forensics and nuclear smuggling incident response.
\end{abstract}

\section{Creation of the ITWG}

The impetus for the Nuclear Smuggling International Technical Working Group (ITWG) came over a decade ago from the recognition that identified international cooperation in nuclear forensic analysis as an effective means to combat nuclear smuggling. At the time, there was acknowledgment that informal communication and cooperation among experts was preferred means to meet this objective. This approach was further endorsed at the G7+1 summit held in Ottawa in 1995 and confirmed in the G7+1 nuclear safety and security summit held in April 1996 in Moscow. The genesis of the ITWG can be traced to the International Conference on Nuclear Smuggling Forensic Analysis held at Lawrence Livermore National Laboratory from November $7-9,1995$ where a total of fourteen countries or international organizations agreed on the desirability of establishing an on-going forum for international cooperation in nuclear forensics.

The terms of reference state that the International Technical Working Group will evaluate present capabilities for combating nuclear smuggling and will:

1) Identify and prioritize techniques and methods for forensic analyses of nuclear materials in order to answer questions regarding sources and intended use of seized nuclear materials. 
2) Identify and prioritize techniques and methods for forensics analyses of nonnuclear materials associated with seized nuclear materials to answer questions regarding geolocation and route attribution.

3) Formulate and execute interlaboratory exercises to evaluate and improve techniques and methods for forensic analysis of seized nuclear materials.

4) Improve to technical capabilities including collection and preservation of evidence, initial on-scene hazard categorization, assessment of nuclear materials composition, identification of applicable national law and statutes, and assistance to states with nuclear forensics as requested.

\section{ITWG terms of reference and affiliations}

The ITWG is an informal association of practitioners of nuclear forensics. The terms of reference for the ITWG do not require sanctioning by any governmental or international body. Each request for nuclear forensic assistance is unique and requires a unique response. The lack of a formal affiliation allows the ITWG to provide a tailored forensics response to requesting states without the complexities required by more formal endorsements or recognition. The G-8's Nuclear Safety and Security Group and other foreign ministries recognize the working group as the international collective for the best practice in nuclear forensics.

The ITWG also works together with the International Atomic Energy Agency. As identified by its own Consultant's Group, the International Atomic Energy Agency (IAEA) can refer requesting states to the ITWG for international assistance in nuclear forensics investigations. An interested state contacts the IAEA to evaluate the need for nuclear forensics and to obtain information on, and access to, ITWG capabilities. The ITWG provides the IAEA with a point-of-contact for a spectrum of nuclear forensics assistance as well as a means to provide mutual assistance in nuclear forensics investigations.

\section{Meetings and organization of the ITWG and its task groups}

The ITWG is open to all states interested in nuclear forensics. Each state funds its own participation; in certain instances, states can also request international assistance to underwrite their expenses. Since 1996 the ITWG has met annually at meetings hosted by participating states in Europe and Russia. Table I is a summary compilation of the meetings conducted to date. Each state sends its own delegation of technical and law enforcement representatives to the annual meeting as well as interested governmental representatives. Over the years this approach has resulted in a mix of attendees some with collective knowledge garnered from attending several ITWG meetings and others who as new members bring fresh perspectives and insights to the group. 
Table I. Summary and locations of ITWG meetings $1995-2007$

\begin{tabular}{lll}
\hline Meeting & \multicolumn{1}{c}{ Location } & \multicolumn{1}{c}{ Date } \\
\hline & & \\
\hline ITWG-1 & Karlsruhe, Germany & Janury $31-$ February 1, 1995 \\
\hline ITWG-2 & Obninsk, Russia & December 2 -4, 1996 \\
\hline ITWG-3 & Como, Italy & June 10 - 11, 1997 \\
\hline ITWG-4 & London, England & July 10-11, 1998 \\
\hline ITWG-5 & Helsinki, Finland & June 9 $-10,1999$ \\
\hline ITWG-6 & Vienna, Austria & June $8-9,2000$ \\
\hline ITWG-7 & Luxembourg & June 27 - 28, 2002 \\
\hline ITWG-8 & Budapest, Hungary & October 1 - 2, 2003 \\
\hline ITWG-9 & Cadarache, France & June 16 - 17, 2004 \\
\hline ITWG-10 & Prague, Czech Republic & June 6-9, 2005* \\
\hline ITWG-11 & Speyer, Germany & September 26-29, 2006* \\
\hline ITWG-12 & Umeå, Sweden & June 25 - 28, 2007* \\
* includes ITWG and ITWG Nuclear Forensics Laboratories (INFL) meetings
\end{tabular}

The work of the ITWG is overseen by an executive committee, represented by members of the European Commission, the United States, France, Great Britain, and Hungary, and is presently performed in four task groups, each chaired by a task group leader, that are standing committees of experts dedicated to the needs of the international forensic community.

\subsection{First Responders Task Group}

The first responders task group is dedicated to nuclear forensic incident management with a focus on the collection and preservation of forensic evidence while balancing the need to protect law enforcement and criminalists working within a potentially contaminated crime scene. In addition to reviews of country-specific experience in responding to incidents involving the presence of radioactive materials, the task group is proposing to develop a catalogue of previous national first responder exercises that includes an element of nuclear forensics. The catalogue may include a description of the scenario and objectives without a discussion of results or specific capabilities.

\subsection{Guidelines Task Group}

The purpose of this task group is to develop consensus guidelines to be utilized by all analytical laboratories within the ITWG. The guidelines provide a generalized approached to the analytical problem but are not intended to be stringent and documented laboratory procedures. The use of these guidelines will enable intercomparison of results among all of the ITWG laboratories, as well as ensure analytical results that can be best implemented to generate nuclear forensics evidence that can be used in the potential criminal prosecution of illicit trafficking cases in a court of law. Individual guidelines will be developed for analytical techniques specific to nuclear forensics analysis (e.g., measurement of trace element impurities) as well as for materials (e.g. analysis of low enriched uranium oxide nuclear fuel pellets) important to nuclear forensic investigations. 


\subsection{Communication and Outreach Task Group}

The ITWG recognizes that a key objective of the working group is to foster an "association of active practitioners of nuclear forensics" through the development of an international nuclear forensics community. To achieve this objective regular communication with external organizations is a critical requirement. To this end, contacts were established with the European Network of Forensic Science Institutes (ENFSI), with the World Customs Organization (WCO), with Europol and Interpol, and, as noted above, close contact is maintained with the International Atomic Energy Agency (IAEA). The communications and outreach task group launched the ITWG web-site (https://project.nf-itwg.org) in 2004 that serves as a primary means of information exchange among ITWG participants. The secure web-site includes information on the objectives, charter, and organization of the ITWG, future meetings, past meeting reports and archived presentations, and access to ITWG reports and publications. Access to the web-site is protected and may be arranged through a request to the ITWG executive committee.

\section{$3.4 \quad$ Exercise Task Group}

The forensic exercise task group designs and organizes both analytical and as well as scenario-based training aids to improve nuclear forensics response capability. This task group is responsible for conceiving the objective of the exercise, obtaining statements of capability of participating laboratories, scheduling the exercises with the international participants, arranging logistics to execute the exercises, collecting and collating analytical results, and disseminating all findings. As noted, the ITWG has already completed analytical exercises involving plutonium in 1998-2000 and highly enriched uranium in 2000-2002 [1]. In these round robins, a representative nuclear sample was aliquoted equally, shipped to the participating laboratories, and analyzed for forensics signatures (e.g., major and minor isotopes, fission products, major and trace elements, physical characteristics) as an unknown nuclear sample. Laboratories report results anonymously to allow for intercomparison. The purpose of the round robins is not to "grade" individual laboratories in their performance but rather to learn as a community from the results of a coordinated laboratory exercise conducted using a common sample. The exercise task group has planned a third analytical exercise for 2007-2008.

\section{The ITWG and the Model Action Plan}

Recent cooperation on the development and publication of the nuclear forensics model action plan underscores shared objectives of the IAEA and ITWG to deter the illicit trafficking of nuclear materials. Soon after being founded, the ITWG conceived a model action plan for the recommended pursuit of a nuclear forensics investigations. In 2003 the IAEA approached the ITWG about drafting a technical report that described the recommended approach to pursuing nuclear forensic investigations. Documentation of the model action plan includes recommendations concerning incident response to an interdiction event, collection of evidence in conformance with required legal standards, laboratory sampling and distribution of samples, radioactive materials analysis, including categorization and characterization of samples, forensics analysis of conventional evidence, and case development including interpretation of forensic signatures. The model action plan was published 
in 2006 by the International Atomic Energy Agency as Nuclear Security Series No. 2, "Nuclear Forensics Support" has subsequently been adopted by many nations as they prepare and respond to incidents of illicit nuclear trafficking [2]. The sharing of this comprehensive plan is the key component of global coordination in nuclear forensics.

\section{The ITWG Menu of Options}

Because nuclear smuggling cases are each different, resulting nuclear forensic investigations must be tailored to the specific needs of each case. To enable this individual response, the ITWG has developed a "Menu of Options" that allows the group to provide a specific response. Different assistance options may include basic characterization or comprehensive technical studies that enable a full nuclear forensics characterization. Different laboratories offer unique capabilities; multilaboratory versus single laboratory involvement may enhance the confidence in the resulting nuclear forensics interpretation. A "Forensics Management Team" identified a priori can provide a point-of-contact in each country or nuclear forensics laboratory to facilitate evidentiary requirements, external communication, and case development. Finally the menu will specify the extent and timeline of a final nuclear forensics report.

\section{ITWG Nuclear Forensic Laboratories}

As the group has expanded, the need to provide a forum for in-depth technical exchanges dedicated to the improvement of nuclear forensics analytical methods, application of signatures to nuclear forensics investigations, best execution of nuclear forensics analytical exercises and scenario-based response drills has resulted in the creation of the ITWG Nuclear Forensics Laboratories (INFL) as a companion technical organization to house the scientific pursuits of the working group. The affiliate role of the INFL has improved the technical practice of nuclear forensics and thereby directly benefited national and international response in nuclear forensics. The INFL is pursuing a relevant agenda including methods for reliable nuclear and radiological categorization of forensic samples, needs for reference materials in nuclear forensics, and measurement and interpretation trace element signatures in diverse nuclear forensic applications.

\section{Recent Activities}

The past five years has seen a substantive growth in the membership and agenda of the ITWG. Each annual meeting draws larger numbers of participants; at the last meeting in Umeå, Sweden 30 nations and organizations participated. In concert with the larger membership, the ITWG has evolved since its inception in response to the changing nature of the threat posed by nuclear trafficking. At each annual meeting a critical part of the agenda is a review of the application of nuclear forensics in response to the unauthorized trafficking of nuclear contraband. Central to this endeavor is the review of country-specific responses to illicit trafficking that incorporate requirements for nuclear forensics, radiation measurements, and data interpretation to counter the threat of nuclear terrorism. Recent topics include experience in border and internal security incident response, lessons learned from forensics casework, evaluation of nuclear smuggling trends, developments of multinational partners in nuclear forensics including the International Atomic Energy 
Agency and the European Commission, the need for and outcome of nuclear forensics engagement with the international community, and companion policy and statutory developments that pertain to nuclear forensics to best address the threat from nuclear smuggling.

The ITWG is actively expanding its membership to regions concerned by the illicit trafficking of nuclear materials. A directive from the G-8 is to increase its membership to states that are interested in developing their indigenous capability to deter illicit trafficking. Over the past years nuclear forensics experts from Tajikistan, Kyrgyzstan, Kazakhstan, and South Korea have attended the meetings for the first time. As well, the addition of Russian-English language interpretation services has enabled scientists from the Russian Federation and newly independent states to fully engage in the technical discourse of the meetings. This has facilitated scientific exchange and enabled necessary collaborations with essential partners. While the ITWG holds its annual meeting at a central location, a recent proposal for distributed regional meetings convened in localities directly affected by nuclear smuggling offers additional benefits by extending nuclear forensics expertise to those that most need the assistance.

The ITWG is active in outreach to inform the international community of the threat posed by illicit trafficking, the need to effective prosecute these crimes, and the capabilities available to collect evidence linking perpetrators to their nuclear contraband. In 2007 the ITWG has provided a summary of it activities at a recent meeting of the G-8's Nuclear Safety and Security Group (NSSG), participated in the International Nuclear Terrorism Law Enforcement Conference sponsored by the Global Initiative to Combat Nuclear Terrorism, and has been featured in a number of publications and nuclear security forums [3].

\section{REFERENCES}

[1] G. B. DUDDER, R.C. HANLEN, and G.M.J. HERBILLION, Advances in Destructive and Non-Destructive Analysis for Environmental Monitoring and Nuclear Forensics, International Atomic Energy Agency, IAEA-CN-98/8 (2003) p. 41-51.

[2] INTERNATIONAL ATOMIC ENERGY AGENCY, Nuclear Forensics Support, Nuclear Security Series No. 2 (2006) 67p.

[3] K. MAYER, M. WALLENIUS, and I. RAY, Nuclear forensics - a methodology providing clues on the origin of illicitly trafficked nuclear materials, The Analyst 130 (2005) 443. 